\title{
Preparedness for advancing future health: a national qualitative exploration of dietetics graduates' experiences
}

\author{
Kate Morgan $^{1}$ (D) $\cdot$ Katrina L. Campbell $^{1}$ (D) . Sally Sargeant ${ }^{2}$ (D) $\cdot$ Dianne P. Reidlinger $^{1}$ (D)
}

Received: 7 November 2018 / Accepted: 29 July 2019

(c) Springer Nature B.V. 2019

\begin{abstract}
Effective health workforce preparation is critical to the health of those who stand to benefit from its services. Emerging dietitians can provide important insights on an evolving workforce that is well-placed to advance future global health. This study aimed to explore a national sample of dietetics graduates' experiences of, and challenges faced in, dietetics workforce preparation and preparedness in Australia. An interpretive description methodology guided this study whereby researchers interpreted the meanings that participants attributed to their experiences. Twenty dietitians (graduated within the last 2 years) were purposively sampled from across Australia and detailed insights were obtained through semi-structured interviews. A multi-analyst approach employing thematic and template analysis, enabled five themes to be identified across the data set. These included: (1) being held back; (2) chasing the prize; (3) valuing real learning; (4) easing the transition; and (5) encountering influencers. While graduates appreciated their preparation, they were not empowered or equipped to embrace opportunities in diverse and emerging areas of dietetics practice. Graduates were challenged by the competitive landscape of securing obvious job opportunities and by a lack of support in transitioning into the workforce. Practice exposures and encounters with influential dietitians were highly valued. Research on roleemerging dietetics placements along with enhanced support mechanisms for novice dietitians is urgently required to ensure appropriate alignment between future dietetics preparation and practice. Obtaining insights into health professional graduates' experiences of their education can be used to ensure that emerging health workforces are relevant and responsive to future market needs.
\end{abstract}

Keywords Dietetics education · Educators · Graduates · Preparedness for practice · Qualitative research · Students · Workforce

Kate Morgan

kmorgan@bond.edu.au

1 Faculty of Health Sciences and Medicine, Bond University, Gold Coast, QLD 4226, Australia

2 School of Health and Human Sciences, Southern Cross University, Coolangatta, Australia 


\section{Introduction}

Ensuring appropriate workforce preparation and preparedness is a common issue across health professions. Since the Institute of Medicine (2003) reported that health professional graduates were not adequately prepared to practice, a body of evidence regarding graduate preparation and preparedness has emerged across many health disciplines. For example, the experience of recent graduates has been explored to identify the areas where graduates might be better prepared in medicine (Morrow et al. 2012; Kellett et al. 2015; Barr et al. 2017) and occupational therapy (Hodgetts et al. 2007; Gray et al. 2012). Research has also highlighted the role of practice experiences to improve confidence in graduate employment for a number of disciplines including nursing (Halcomb et al. 2012; Hatzenbuhler and Klein 2018) and physiotherapy (Atkinson and McElroy 2016). Other studies across physiotherapy, pharmacy and medicine have highlighted employability and transferable skills as shortcomings for students and graduates (Jones et al. 2010), the role of professional identity formation (Noble et al. 2014) and the benefits of evaluation of university programs to improve curriculum and meet accreditation requirements (Kairuz et al. 2010). Although discipline-specific, such scholarship is relevant across all health professions and has a role in improving the future health workforce.

Preparing an effective health workforce involves equipping graduates with an appropriate range of attributes across a diversity of contexts to meet the health care needs of the individuals and populations they will serve (World Health Organization 2006). The ageing population and the rising prevalence of chronic conditions and multimorbidity has led to calls for a focus on generalist practice preparation, rather than specialist training. This approach aims to promote a whole-person focus, to more effectively manage complex conditions, and to meet the shortages of health professionals in rural and regional locations (Hudson et al. 2017). Such calls have highlighted the role of curriculum design and practice-based learning to support policy initiatives and to provide the skills and experience required by practitioners operating within an increasingly complex health care landscape. Emerging evidence has demonstrated the association between nutrition and the increasing international issue of multimorbidity (Ruel et al. 2014). Given the clear role nutrition plays in achieving optimal health throughout the life course (Darnton-Hill et al. 2004), the emerging dietetics workforce is well-placed to impact future health globally.

Dietetics is a health profession that has grown substantially in recent years (Health Workforce Australia 2014; International Confederation of Dietetic Associations 2016) and is witnessing a significant expansion in breadth of practice areas (Hickson et al. 2017; Kicklighter et al. 2017; Dietitians Association of Australia 2018c). Although traditionally dietitians have been employed in three main areas of practice (clinical dietetics-practised predominantly in hospital and outpatient settings; food service dietetics_-focused on menu and food service systems to meet the needs of individuals in institutional settings; and public health and community nutrition-applying primary prevention principles to individuals and groups) (Morgan et al. 2019c), there is increasing awareness of the diverse range of roles that dietitians work across (Dietitians Association of Australia 2018c). The dynamic and evolving nature of the dietetics profession signals that the dietetics workforce and the outcomes of its preparation warrant attention. In Australia, graduates of accredited dietetics education programs must demonstrate competence through a Bachelor-level degree at minimum, which includes 100 days $(\sim 800 \mathrm{~h})$ of practice placement experience (Dietitians Association of Australia 2017, 2018a). In order to satisfy credentialing requirements to become an accredited practising dietitian (APD), graduates must participate in a year-long 
mentoring partnership as a 'provisional' dietitian followed by continuing professional development (Dietitians Association of Australia 2018b). As a non-registered profession, dietetics does not benefit from the workforce data collection services afforded to registered health professions in Australia (Australian Health Practitioner Regulation Agency 2018). A lack of robust workforce data has been widely acknowledged as an ongoing issue in evaluating this emergent profession (Brown et al. 2006; Dietitians Association of Australia 2012; Health Workforce Australia 2014).

As key stakeholders embedded in the phenomena, recent graduates are ideally situated to provide insights into health workforce preparation and their preparedness for practice. Further, given the marketisation of university degrees and rise of the 'student-as-consumer' approach in higher education (Tomlinson 2016; Bunce et al. 2017), graduate perspectives on their training should be valued by health professional educators. Despite the existing body of literature, few studies in other disciplines have taken a national approach, with most sampling graduates (or sometimes students) from a single university or within states/regions of a country. In addition, perspectives provided in many studies have focused on a specific aspect (e.g. preparedness for working in one area of practice) or have been restricted to a quantitative survey with open-ended comments yielding minimal understanding about individuals' experiences.

Existing scholarship in dietetics on this topic is similar. Qualitative investigations of recent graduates' experiences of their preparation and/or preparedness have focused on specific aspects such as placements (Maher et al. 2015), assessment (Palermo et al. 2015), mentoring (Palermo et al. 2011), and professional identity development (Brady et al. 2012). Graduates perspectives on their preparedness for practice have also been investigated through surveys which have provided limited in-depth insights (Rose et al. 2005; Brissette et al. 2014). Other key stakeholders in dietetics workforce preparation, including academic and practice educators, have provided their views on the issues faced by recent dietetics graduates in Australia. These studies have revealed that newly-qualified dietitians are likely challenged by competition for jobs due to an apparent oversupply of graduates prepared for mostly 'traditional' areas (e.g. clinical dietetics) which has been attributed, in part, to rigid program accreditation requirements (Morgan et al. 2018, 2019b). While these insights are valuable, it is the richly detailed descriptions obtained through qualitative explorations of those individuals who have experienced the phenomena themselves (i.e. graduates) which hold great value. Such insights could add to the existing body of literature across other health professions, to enable the identification of shared challenges experienced in workforce preparation and preparedness.

A national approach to investigating newly qualified dietitians' broad experiences of their education and work-readiness is lacking. The aim of this study was to explore recent dietetics graduates' experiences of, and challenges faced in, dietetics workforce preparation and preparedness in Australia.

\section{Materials and methods}

\section{Study design and researcher position}

This qualitative study adopted a social constructionist epistemological position (that multiple realities are constructed by research participants' through their social interactions) and an interpretive theoretical perspective (that meaning is derived from how the research 
participants interpret their experience of a phenomenon) (Crotty 1998; Creswell 2013; Willig 2013). Applying an interpretive description methodology enabled researchers to capture themes and patterns in the data by interpreting participants' subjective experiences and gaining an understanding of a complex phenomenon-in this context, their experience of workforce preparation and preparedness (Hunt 2009; Thorne 2016). In line with the above approaches, interviews were the chosen enquiry method (Liamputtong 2013). Data were also considered against the theoretical framework of self-determination theory (that individuals are intrinsically motivated by the satisfaction of their need for fulfillment) in order to understand the motivations driving participants' behaviour (Ryan and Deci 2000; Ten Cate et al. 2011).

The research team consisted of four females-all who were health professional educators in higher education institutions working in the discipline of dietetics (KM, DR and $\mathrm{KC}$ ) or health sciences (SS). All researchers were experienced in qualitative research and had previously been involved in similar studies which investigated the experiences of stakeholders (i.e. academic educators, practice educators) in dietetics workforce preparation (Morgan et al. 2018; Morgan et al. 2019b). Given these experiences, the researchers were of the view that recent dietetics graduates could have valuable insights to share regarding dietetics workforce preparation and preparedness. The reporting of this study was guided by the standards for reporting qualitative research (SRQR) (O'Brien et al. 2014). Ethical approval was obtained from the Bond University Human Research Ethics Committee.

\section{Participants and recruitment}

In order to sample informants who were well-placed to describe their experience of the phenomenon of interest, participants were required to: (1) be a graduate of an accredited dietetics program in Australia; and (2) have completed their dietetics qualification within the 2 years prior to this study commencing. Participants could have been working as a dietitian or otherwise and could have been located in any state or country. Recruitment began in April 2016 and was completed by May 2016. Purposive and maximum variation sampling were used to ensure a national sample of eligible participants from a variety of sites across the country who could provide pertinent insights to address the research aim (Patton 2015; Creswell and Poth 2018) and to enhance transferability (Liamputtong et al. 2017). Invitations to participate in the study were electronically distributed via the Dietitians Association of Australia (DAA) weekly member newsletter ( $\mathrm{n} \approx 6269)$ and to relevant DAA member interest groups (e.g. the Emerging Dietitians Interest Group), as well as through the weekly newsletter of an Australian-based, international network of dietitians $(\mathrm{n} \approx 6000)$ (Dietitian Connection). Those who expressed interest in participating were emailed an explanatory statement (including details of the study and assurance of confidentiality) as well as an interview guide. Respondents were asked to contact the first author $(\mathrm{KM})$ to arrange a time for their interview. Informed consent was obtained from all individual participants included in the study. To help incentivise participation, two gift vouchers randomly drawn from the pool of participants were offered as a prize to those taking part.

\section{Data collection}

In-depth, semi-structured interviews with each individual participant were all conducted by the first author (KM). The interview guide was adapted from a recent study conducted with other key stakeholders involved in dietetics workforce preparation (Morgan et al. 
2019b). Questions were: designed to address the study's aim; influenced by the research team's approach and positionality; and informed by a lack of evidence regarding dietetics graduates' broad experiences. The interview guide was piloted with one dietetics graduate and minor modifications were made to phrasing to enhance question clarity. The final interview guide included seven open-ended questions designed to capture detailed insights from participants about their experiences (Table 1). At the commencement of the interview, participants were asked to verbally confirm their informed consent. To ensure that the sample could be described, participants were also asked to answer closed questions regarding demographic information and professional attributes. The semi-structured nature of the interview meant that question order could be modified and question phrasing could be expanded or clarified by the interviewer as required. Interviews were conducted via telephone (as participants were located in different settings across Australia) at a time that was mutually convenient for interviewee and interviewer (who were not known to each other prior to the study). Field notes were made (KM) throughout and shortly after each interview to enhance confirmability, highlight key responses and record relevant researcher thoughts. Interviews lasted between 26 and 63 min (average: $36 \mathrm{~min}$ ) and were digitally recorded then de-identified before being provided to a professional transcription service. The first author (KM) listened to each audio recording and checked the accuracy of each transcription (with minor corrections made where required) prior to analysis.

\section{Data analysis}

Thematic analysis, as described by Braun and Clarke (2006), guided the development of themes from the data and was carried out primarily by two members of the research team (KM \& DR) with another author (SS) cross-checking their findings and providing additional perspectives. To aid analysis, verbatim transcripts were imported into QSR NVivo (Version 11). Each transcript was read multiple times by the first author (KM) who then conducted open, line-by-line coding of each transcript (Braun and Clarke 2006). All codes in the final coding library $(n=333)$ were exported to a word processing document and printed to enable visual mapping of codes and the inductive development of themes into meaningful clusters.

Table 1 Interview guide for exploring dietetics graduates' experiences of workforce preparation and preparedness

\begin{tabular}{ll}
\hline Question & Enquiry logic \\
\hline $\begin{array}{l}\text { How did you come to be studying nutrition and } \\
\text { dietetics at university? }\end{array}$ & $\begin{array}{c}\text { Pathway into and motivations for becoming a } \\
\text { dietitian } \\
\text { Own experience of workforce preparation }\end{array}$ \\
$\begin{array}{l}\text { Describe your experience of being prepared as a } \\
\text { dietitian for the workforce in Australia }\end{array}$ & $\begin{array}{l}\text { Pedagogical exposures and influence on preparation } \\
\text { were used to prepare you for the dietetic workforce }\end{array}$ \\
$\begin{array}{c}\text { Describe any challenges that face dietetic students } \\
\text { being prepared as dietitians for the workforce }\end{array}$ & $\begin{array}{c}\text { Views on challenges faced by self and others during } \\
\text { preparation }\end{array}$ \\
$\begin{array}{c}\text { Describe your experience of being a dietetic graduate } \\
\text { entering the workforce }\end{array}$ & $\begin{array}{c}\text { Own experience of entering workforce } \\
\text { How well prepared did you feel as a dietitian enter- } \\
\text { ing the workforce? }\end{array}$ \\
$\begin{array}{c}\text { Describe any challenges faced by dietetic graduates } \\
\text { entering the workforce today }\end{array}$ & $\begin{array}{c}\text { Views on own preparedness for practice } \\
\text { entering workforce }\end{array}$ \\
\hline
\end{tabular}


Prior to analysis, a second author (DR) reviewed a sample of transcripts from participants with a diverse range of views $(n=5)$ as well as the entire coding library to enhance familiarity with the participants' perspectives. To acknowledge the likely influence of findings from the previous, similar studies that the research team had been involved in (with dietetics students, educators and supervisors), template analysis was incorporated (Brooks et al. 2015). Here the themes and subthemes from those studies acted as an a priori template for initiating the analytic process. Over a series of meetings, two members of the research team $(\mathrm{KM} \& \mathrm{DR})$ analysed a randomly-selected subset of data $(\mathrm{n}=8)$ which provided a sound cross-section of participant experiences against the template. Where existing themes did not confer a good fit, they were modified into new preliminary themes that captured the major recurrent patterns occurring throughout the data subset. The authors then commenced inductive analysis with the entire data set $(n=20)$, whereby the preliminary themes were applied to all codes until theoretical sufficiency was reached (Varpio et al. 2017). This was the point at which the authors agreed that adequate and appropriate data had been collected and analysed to address the research aim, and that the addition of new data would not alter the themes identified (Dey 1999; Varpio et al. 2017). Multiple meetings and discussions took place as themes and subthemes were modified, progressed and refined. To enhance dependability that the findings 'fit' the data (Liamputtong et al. 2017) and to enable multiple researcher perspectives (Varpio et al. 2017), a third author (SS) reviewed a sample of transcripts $(n=5)$ against the themes and subthemes that had been developed. Minor adjustments were made until all authors (KM, DR \& SS) reached consensus that the themes and subthemes provided an accurate representation of the data and the study's aim had been addressed. Verbatim quotes that captured the meaning behind the themes and subthemes were extracted from the participants' transcripts and tabulated to enhance confirmability (Liamputtong et al. 2017). Participant checking of transcripts or themes was not carried out nor were any repeat interviews conducted with participants. Participant demographic information was manually entered into SPSS (Version 23) to generate frequency distributions of the sample's professional characteristics.

\section{Findings}

Twenty recent dietetics graduates provided informed consent and participated in the study. A further thirty-one responded to the invitation to participate but were either not required due to sufficient data being collected to address the study's aim $(n=5)$ or did not respond further once additional information about the study was provided $(n=26)$. The majority of participants were female $(90 \% ; 18 / 20)$ provisional accredited practising dietitians (APDs) $(65 \% ; 13 / 20)$, who were employed as dietitians $(90 \% ; 18 / 20)$ on a full-time basis $(65 \%$; $13 / 20)$. One quarter $(5 / 20)$ had completed their dietetics degree in the state of Victoria and the average age of participants was 30 years. Full characteristics of the participant sample is provided (Table 2).

Analysis identified five main themes from the data: (1) being held back; (2) chasing the prize; (3) valuing real learning; (4) easing the transition; and (5) encountering influencers. De-identified participant quotes were selected to convey the meaning captured within the themes and to illustrate the subthemes that underpinned them (Table 3). The themes and subthemes are described below and graphically presented (Fig. 1). The terms 'student' and 'graduate' are used interchangeably as participants were reflecting on their experience of being both a student (preparation) and a graduate (preparedness). 
Table 2 Characteristics of recent dietetics graduates $(n=20)$ interviewed in this study

\begin{tabular}{|c|c|}
\hline Attribute & Number of participants \\
\hline \multicolumn{2}{|l|}{ Gender, n (\%) } \\
\hline Female & $18(90)$ \\
\hline Male & $2(10)$ \\
\hline Age, mean \pm SD & $30.2 \pm 10.1$ \\
\hline \multicolumn{2}{|l|}{ Current APD ${ }^{\mathrm{a}}$ status, n (\%) } \\
\hline Provisional APD & $13(65)$ \\
\hline APD & $7(35)$ \\
\hline \multicolumn{2}{|l|}{ State in which dietetics degree undertaken, $\mathrm{n}(\%)$} \\
\hline Australian Capital Territory & $2(10)$ \\
\hline New South Wales & $3(15)$ \\
\hline Queensland & $4(20)$ \\
\hline South Australia & $3(15)$ \\
\hline Victoria & $5(25)$ \\
\hline Western Australia & $3(15)$ \\
\hline \multicolumn{2}{|l|}{ Current state/territory of residence/employment } \\
\hline Australian Capital Territory & $3(15)$ \\
\hline New South Wales & $3(15)$ \\
\hline Northern Territory & $1(5)$ \\
\hline Queensland & $4(20)$ \\
\hline South Australia & $1(5)$ \\
\hline Victoria & $4(20)$ \\
\hline Western Australia & $4(20)$ \\
\hline \multicolumn{2}{|l|}{ Level of dietetics degree completed } \\
\hline Bachelor/Bachelor (Honours) & $5(25)$ \\
\hline Masters & $15(75)$ \\
\hline \multicolumn{2}{|l|}{ Duration of dietetics degree completed } \\
\hline 1.5 years & $4(20)$ \\
\hline 2.0 years & $11(55)$ \\
\hline 4.0 years & $5(25)$ \\
\hline Months since completing dietetics degree, mean \pm SD & $10.2 \pm 6.2$ \\
\hline \multicolumn{2}{|l|}{ Current employment status as a dietitian } \\
\hline Employed/working & $18(90)$ \\
\hline Unemployed/seeking work & $2(10)$ \\
\hline \multicolumn{2}{|l|}{ Current appointment status as a dietitian } \\
\hline Full-time & $13(65)$ \\
\hline Part-time & $2(10)$ \\
\hline Casual & $3(15)$ \\
\hline N/A & $2(10)$ \\
\hline \multicolumn{2}{|l|}{ First appointment status as a dietitian } \\
\hline Full-time & $9(45)$ \\
\hline Part-time & $4(20)$ \\
\hline Casual & $5(25)$ \\
\hline N/A & $2(10)$ \\
\hline Months taken to begin work/employment as a dietitian, mean $\pm \mathrm{SD}$ & $1.0 \pm 1.3$ \\
\hline \multicolumn{2}{|l|}{ Months taken to begin work/employment, n (\%) } \\
\hline 0.0 -Commenced work immediately after completing degree & $7(35)$ \\
\hline
\end{tabular}


Table 2 (continued)

\begin{tabular}{|c|c|}
\hline Attribute & Number of participants \\
\hline$\leq 1.0$ & $5(25)$ \\
\hline $1.1-2.0$ & $3(15)$ \\
\hline $2.1-3.0$ & $2(10)$ \\
\hline $3.1-4.0$ & $1(5)$ \\
\hline N/A-not currently in paid work/employment as a dietitian & $2(10)$ \\
\hline Months of experience working as a dietitian, mean \pm SD & $8.3 \pm 6.9$ \\
\hline \multicolumn{2}{|l|}{ Months of experience working as a dietitian, $\mathrm{n}(\%)$} \\
\hline $0.1-6.0$ & $9(45)$ \\
\hline $6.1-12.0$ & $3(15)$ \\
\hline $12.1-18.0$ & $4(20)$ \\
\hline $18-24$ & $2(10)$ \\
\hline N/A-not currently working/employed as a dietitian & $2(10)$ \\
\hline Total hours worked per week as a dietitian, mean \pm SD & $30.9 \pm 14.0$ \\
\hline \multicolumn{2}{|l|}{ Total hours (paid and unpaid) worked per week as a dietitian, $\mathrm{n}(\%)$} \\
\hline 0.0 & $1(5)$ \\
\hline $0.1-16.0$ & $3(15)$ \\
\hline $16.1-32.0$ & $4(20)$ \\
\hline $32.1-40.0$ & $9(45)$ \\
\hline$>40$ & $3(15)$ \\
\hline Total paid hours worked per week as a dietitian, mean \pm SD & $28.6 \pm 16.0$ \\
\hline \multicolumn{2}{|l|}{ Total paid hours worked per week as a dietitian, n (\%) } \\
\hline 0.0 & $2(10)$ \\
\hline $0.1-16.0$ & $3(15)$ \\
\hline $16.1-32.0$ & $3(15)$ \\
\hline $32.1-40.0$ & $9(45)$ \\
\hline$>40$ & $3(15)$ \\
\hline Total unpaid hours worked per week as a dietitian, mean \pm SD & $2.6 \pm 4.7$ \\
\hline \multicolumn{2}{|l|}{ Total unpaid hours worked per week as a dietitian, n (\%) } \\
\hline 0.0 & $12(60)$ \\
\hline $0.1-4.0$ & $4(20)$ \\
\hline $4.1-8.0$ & $2(10)$ \\
\hline $8.1-12.0$ & $2(10)$ \\
\hline \multicolumn{2}{|l|}{$>12.0$} \\
\hline \multicolumn{2}{|l|}{ Main area of practice since graduating } \\
\hline Aged care & $1(5)$ \\
\hline Clinical & $4(20)$ \\
\hline Community & $3(15)$ \\
\hline Food industry & $1(5)$ \\
\hline Health promotion & $1(5)$ \\
\hline Media and communications & $1(5)$ \\
\hline Private practice & $4(20)$ \\
\hline Research & $3(15)$ \\
\hline N/A & $2(10)$ \\
\hline
\end{tabular}

${ }^{\mathrm{a}} A P D$ accredited practising dietitian 
Table 3 Illustrative quotes from dietetics graduates regarding their experience of workforce preparation and preparedness

\begin{tabular}{|c|c|}
\hline Theme/subtheme & Participant quotations \\
\hline \multicolumn{2}{|l|}{ 1. Being held back } \\
\hline $\begin{array}{l}\text { 1a. Appreciating prepara- } \\
\text { tion }\end{array}$ & $\begin{array}{l}\text { "The course was fantastic. I wouldn't want to talk it down but I do think it's } \\
\text { largely clinically focused, which for anybody who goes into a different field it's } \\
\text { a bit more difficult." RG086 } \\
\text { "I think the foundation that university provides is a solid foundation in terms of } \\
\text { dietetic practice." RG063 }\end{array}$ \\
\hline 1b. Feeling let down & $\begin{array}{l}\text { "I felt (my preparation) was a bit brushed over very quickly. It was kind of just, } \\
\text { how to get through placement, not how to finish uni and progress into the } \\
\text { future...it was either being a hospital dietitian or nothing." RG091 } \\
\text { "Letting (students) know that it is quite difficult to get a job...we were never given } \\
\text { that impression. We just thought we'd go out into the workforce, there'd be a } \\
\text { job, and everything would be right." RG068 }\end{array}$ \\
\hline 1c. Missing opportunities & $\begin{array}{l}\text { "You're taught as if you're going to go and work in a hospital and that's all they're } \\
\text { really taking care of for you. Whereas in reality, the majority don't end up in that } \\
\text { setting." RG088 } \\
\text { "We did a placement in food service and I don't know anyone who has a job in } \\
\text { food service, and I don't know anyone that really wants one in that... maybe } \\
\text { figuring out where the jobs are for the graduates, where the graduates are going } \\
\text { and finding something that is more suited to that, to teach them." RG082 }\end{array}$ \\
\hline
\end{tabular}

\section{Chasing the prize}

2a. Competing with others

2b. Unrelenting knocks

2c. Reaping the rewards
"The main challenge is there are too many graduates for the number of jobs... you're competing with 100-plus people when you apply for a job and many of them have banked up from the year or two before you and...they have a bit more experience." RG082

"There's a lack of positions available for the amount of graduates there are...it's hard, everybody has the same degree essentially and has done the same placements as required by DAA." RG087

Divergent:

"The majority of my peers do have work, whether it's bits of work or full-time work... The idea was that it would be really hard, and it hasn't been as hard as that." RG075

"It's a shame because you come out so enthusiastic, so ready to learn, and you've put all your efforts into doing something... but you get knocked back...it's very difficult." RG087

"It's so difficult to find work when you finish, it just destroys your motivation... I've moved to [city] to improve my chances, without knowing anyone, it's very hard to know where to start. I don't really know where to go, I know I need to get a foot inside the door, but...it's really difficult and frustrating." RG077

"You need to set yourself apart from other people.... a huge percentage of my cohort focused so hard on getting the best grades that they could...they've got amazing academic transcripts... but unfortunately when it's so hard to get a job, it's the people that have experience outside of uni that are going to stand out." RG079

"I knew that networking was going to get me career ready but at the same time not studying for an exam as much as I should, because I was out talking to dietitians and networking, was a dilemma for me. I think most people chose one or the other." RG067

Divergent

"I did heaps of volunteering....all over the place, but I didn't find that it actually helped me at all in getting a job." RG062 
Table 3 (continued)

Theme/subtheme Participant quotations

3. Valuing real learning

3a. Fulfilling aspirations

3b. Missing the link

4. Easing the transition 4a. Flying blind

4b. Going it alone
"The assessments were really good because they were all things that dietitians would do in the workforce. They weren't just for the sake of an assessment task...I can see now that a lot of the assessments we did were very much things that dietitians are paid to do in the real world...that's really important." RG088

"Placement was obviously the highlight... because I was interacting with patients and putting the theory into practice and not just sitting down, listening to someone to talk...that's when things 'stuck'...it's a bit better than sitting in a lecture" RG082

"I got a lot of practical experiences at [university]...they've got a high-tech clinic where clients come in for a free consult and you are supervised...I found that once I was on prac in the hospital or in the community that I already had that client-based experience...that was a really good experience.” RG069

“The first three years...just to say, 'Well, here's the theory. You'll get the practical experience in your final year.' How can we join the relevance in that? That was a massive challenge for us...I found a lot of people in fourth year were going, 'Oh, I didn't realise that's what dietitians did.' It's logical that you apply theory as you practice, as you learn it, rather than two years later." RG072

"The first two years were definitely at times a struggle to see their link to nutrition...it seems like it wasn't $100 \%$ related to being a dietitian...I was kind of thinking, 'Oh, maybe this isn't for me.' But then in third year, when we started doing more practical things...I was really glad that I stuck with it... when I was able to see...those things in action...that was a real confidence boost to me, 'Yes, I will enjoy doing this,' because I did get a little bit lost for a while there." RG080

“(Preparation to) write CV's and cover letters...we had one hour on this. With the difficulties of getting work now, that's something that was missing, career help in general, all the practical tips. A lot of the questions I have right now, I wish that our lecturers would have discussed that with us during hours at uni." RG077

"The transition from being a student to an employee... we don't really know sometimes if we're doing the right thing... we get so much feedback as a student... whereas, once you start working you're just on your own for most of the time" RG082

Divergent:

"I was very fortunate...I feel like our course did prepare us very well for, actually applying for jobs and where you look and how you put together a resume and how you put together a cover letter...the careers centre was really great" RG094

"A lot of new graduates are going into private practice and when you ask for help through the (discussion) boards, a lot of them become quite narky and don't wanna support new graduates... you have questions and you want support...that doesn't happen....it's really hard to find mentors and a lot of them charge a lot of money...support for new grads is zero...the amount to pay for membership (of the professional association) is so huge as a part-time worker...I get nothing from them...it's really disappointing." RG091

"In a hospital, you probably get a lot more interaction and you probably feel more engaged with dietetics because you could discuss things with people on your lunch break...but for private practitioners, we're on our own, we've got no one to talk to." RG071

"I just feel very disconnected from everyone. I know that I'm a new grad...but most days, I'm on my own...you feel pretty isolated from what's going on." RG072 
Table 3 (continued)

\begin{tabular}{|c|c|}
\hline Theme/subtheme & Participant quotations \\
\hline 4c. Having support & $\begin{array}{l}\text { "My (placement supervisor) doubled as a mentor through my provisional period... } \\
\text { it wasn't stressful at all, at first it was a bit overwhelming...because I had high } \\
\text { expectations on myself, but I had a lot of good support.” RG069 } \\
\text { "That initial process (of looking for work) was very stressful, but what I did really } \\
\text { value was the university's career service who have a 'call us as many times as } \\
\text { you like for feedback' policy, so that was really good...I certainly think that } \\
\text { helps.” RG080 }\end{array}$ \\
\hline
\end{tabular}

5. Encountering influencers

(no subthemes identified) "Meeting dietitians in the profession that became mentors and I really admired, that probably formed the path that I have taken... where I'm working in now... (I) really enjoyed the relationships that I formed with people throughout the course...we had some really inspiring lecturers that were doing interesting things in the field...that was really encouraging thinking ahead in my career." RG079

"There were some supervisors who weren't interested in being there at all...they tended to be more harsh and abrasive and sometimes a bit nasty...that doesn't make a particularly good environment for learning. But at one of my placements, they understood that by that stage, you can feel a bit beaten down...they were very positive and very reassuring, and that was definitely something that helped to promote my learning because... a little bit of positive feedback goes a long way when you feel that way." RG068

"My very first placement in clinical...I loved it...I was treated as if I was one of their colleagues rather than a student for most of the time... it was really fantastic, the people that were there and also getting exposure to the area that I really wanted exposure to." RG088

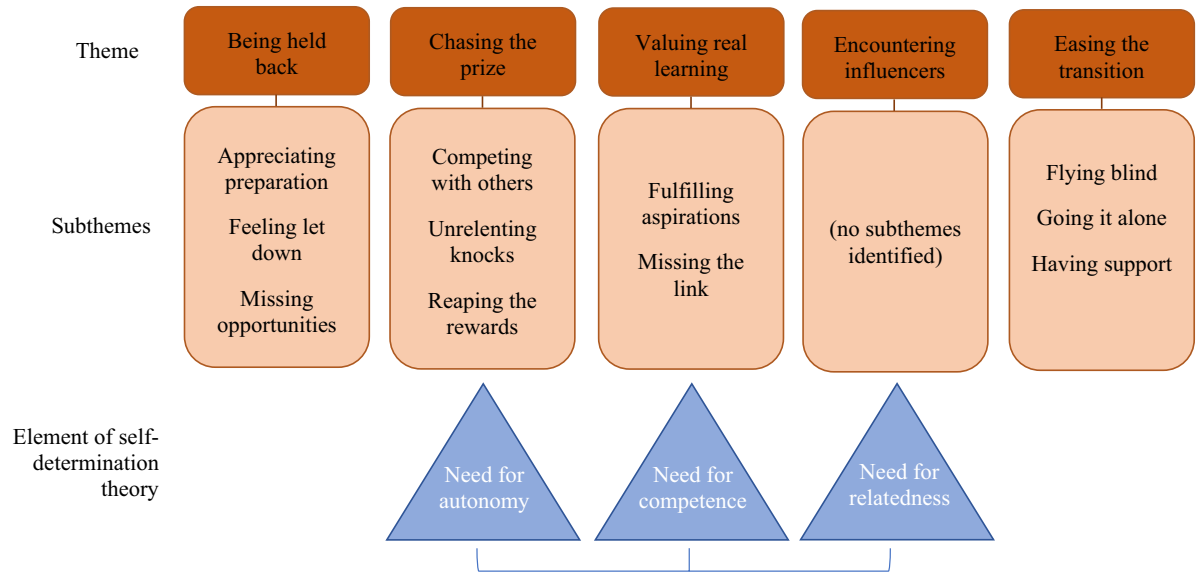

Fig. 1 Themes and subthemes identified from recent dietetics graduates' experiences of dietetics workforce preparation and preparedness

\section{Being held back}

The first theme captured the sentiment that graduates felt they were being held back by their preparation. While graduates generally enjoyed their preparation and reflected on their experience with gratitude, they also felt short-changed and constrained by their 
degrees. Participants described how they were prepared for only a narrow range of dietitian roles and were not well-equipped to embrace wider opportunities.

\section{Appreciating preparation}

Within this subtheme, graduates expressed enjoyment of, and gratitude for, their preparation. Some reported feeling generally well prepared for practice and as though they had a solid foundation upon which to build as a dietitian. In particular, participants felt their programs prepared them well for practice in the area of clinical dietetics. A sense of satisfaction and fulfillment was gained from developing as a nutrition professional and participants reflected 'fondly' upon their degrees, with some even defending and commending their university for its efforts. Despite appreciating their preparation, participants also recognised there were elements of their degrees which constrained their potential.

\section{Feeling let down}

Participants expressed a sense of disappointment and frustration regarding the perceived shortcomings of their preparation. This was due, in part, to graduates' expectations of the workforce not being managed, with some feeling misled or uninformed about the challenging nature of securing work as a graduate dietitian. Some reported that while they were informed about the 'reality' of the workforce, it came too late in their degrees. Graduates felt constrained by their preparation and not empowered to create work opportunities. They also were not encouraged or supported to network with each other or with dietitians in practice. Some participants described feeling short-changed in that their preparation lacked depth, it was misaligned with practice and that addressing mandated competencies/ticking off tasks was prioritised over more meaningful professional development.

\section{Missing opportunities}

Many participants expressed frustration that their degrees had a narrow focus and overemphasis on clinical dietetics which meant they were not prepared for work outside of traditional areas. For example, they described feeling underprepared for establishing a business, for working in a private practice or for counselling patients in a community outpatient setting. This meant that graduates were not well equipped and were missing opportunities to pursue work in emergent areas. While the challenge for university degrees to fit these 'missing' aspects into already full curricula was acknowledged, participants felt that changes to reflect workforce needs was necessary. In addition, graduates frequently referred to their overall preparation and preparedness in relation to three main areas of practice (i.e. clinical, community and/or public health, and food service) while acknowledging that 'other' opportunities outside these areas existed.

\section{Chasing the prize}

Graduates' efforts to chase the elusive prize of securing work as a dietitian was apparent within the second theme. A perceived excess supply of graduates and low demand for 
obvious graduate roles, saw graduates ardently competing against their peers. While this took an emotionally draining toll on graduates, others who made intentional efforts to differentiate themselves reaped the rewards of their endeavours.

\section{Competing with others}

This subtheme captured the widely expressed sentiment that graduates were challenged to secure work and obtain employment. The perceived oversupply of graduating dietitians meant that the job market was flooded with dietetics graduates who found the search for work highly competitive. One participant even described how this intense competition had impacted peer friendships and collegiality. Despite acknowledgement by some participants that there was a need for more dietitians in today's workforce, it was the lack of obvious (advertised) job opportunities that was problematic. Some felt that the professional association and/or universities were exacerbating the issue by producing a surplus of graduates with similar skills and that student numbers needed to be regulated. Divergent views were expressed by some graduates who found securing work easy and felt that graduates were putting unnecessary pressure on themselves in their quest for a job.

\section{Unrelenting knocks}

The emotional toll of the difficulties graduates experienced in securing work was described as stressful, demoralising, depressing and daunting. Despite being enthusiastic and feeling ready to embrace work, participants were challenged by the seemingly insurmountable task of gaining paid work/employment as a dietitian. Some participants were disheartened by receiving many rejections from job applications, by having to apply for non-dietetics positions and by feeling unprepared to apply for some roles. Several expressed a potentially divergent view that finding work was quick and easy. However, those who did secure work with relative ease, felt fortunate as they knew many of their peers were struggling to do the same. Some graduates moved to another state/territory and others begrudgingly changed their career preferences in an attempt to obtain any kind of dietetics work.

\section{Reaping the rewards}

Those participants who took ownership of their situations and showed initiative in their workforce transitions, reaped the benefits of their endeavours. They recognised early in their preparation that students and graduates who went 'outside the box' and differentiated themselves, were able to enter the workforce with ease and initiate a successful career. Some believed that despite the competition for obvious/advertised jobs, many opportunities for working as a graduate dietitian existed, they just needed to be created and pursued. However, some of these enterprising graduates still viewed themselves as 'lucky' to have readily secured work, in comparison to the majority of their peers. Participants reported taking strategic action to 'fill the voids' of their degree while they were still at university to enhance their employability, with activities such as work experience, volunteering and networking. It was also acknowledged by some participants that students who prioritised getting good grades over having additional dietetics-related experiences and who didn't act early in their degree to advance their professional development, were doing so to their detriment. 


\section{Valuing real learning}

Perspectives evident in the third theme related to how participants valued learning which was 'real'. As students they were empowered to fulfil their aspirations to become a dietitian through being able to actively 'do' rather than just having to passively 'listen'. A perceived lack of integration between theory and practice limited their motivation and professional development.

\section{Fulfilling aspirations}

When participants engaged in practical, hands-on and experiential activities throughout their programs, they were able to realise their aspirations of being a dietitian. Those 'realworld' and 'real-life' exposures where students could implement the theory they had previously learned, were highly valued. This meant that placement was regarded as a highlight of their preparation by many participants. Similarly, practical activities in the university setting were also looked upon favourably by students in enhancing their preparedness for placement and future practice. Participants reported that while some activities (such as simulations and role plays) were not enjoyable at the time, they provided a valuable learning experience. There was also some variation around the utility of didactic activities such as lectures. Activities that were also seen as supplementary to the standard curriculum and that showcased the diversity of dietetics practice, were deemed as highly beneficial to students' professional development and desire to be a dietitian.

\section{Missing the link}

Participants described a disconnect between the theory and practice elements of their degrees. Because of this, some struggled to understand the relevance of the content they were being taught early in their degrees. Others even reported feeling lost, disengaged and questioned their aspirations to become a dietitian. Often it wasn't until students had a placement or practice experience, which was usually towards the end of their degree, that the relevance of theory was realised. This impacted students' placement experience which was described as intense, overwhelming and a massive challenge. Participants recognised activities and assessment tasks that genuinely mirrored the work of dietitians in practice as beneficial, rather than being 'just for the sake of it.' Graduates reported that better and earlier integration of theory and practice could enhance the relevance of pedagogical activities and overall student experience.

\section{Encountering influencers}

Within the fifth theme, there was a strong sense of acknowledgment for the integral role that certain people and events played in influencing future dietitians' careers. Connections provided valuable career currency for students and opened their eyes to the possibilities in dietetics careers.

Encounters with influential individuals were valued by graduates. Participants described how the engagement, encouragement and entrustment from placement supervisors solidified their aspirations and boosted their motivation. By contrast, placement settings with unwelcoming cultures and supervisors who were 'nasty' or disengaged created a negative learning environment which evoked frustration and despondence in students. Some 
graduates found lecturers inspiring and rated a lecturers' passion for their work as proportional to the utility of the content being taught. Connections made with dietitians in practice and academia were linked with enhanced employability, resulting in a 'it's who you know' mentality for some participants. Hearing from 'real' dietitians in practice (e.g. guest speakers) brought life to the possible careers that emerging dietitians could pursue. Some encounters with people and placements were so influential, they prompted students to change their career preferences and to pursue another area of dietetics practice.

\section{Easing the transition}

The fourth theme encapsulated graduates' experience of entering into the workforce after gaining their dietetics qualification. The transition from student to practitioner was imbued with a lack of guidance which left graduates feeling daunted and isolated. Those participants who felt well-supported by mentors' advice cherished this direction and support.

\section{Flying blind}

Participants raised that they were not well prepared for and lacked guidance in entering the workforce. This left graduates feeling as though they were 'lost' and blindly trying to navigate the landscape of securing work as a dietitian. Those who did receive assistance with career development activities (e.g. preparing CVs, addressing selection criteria, answering interview questions) often felt it came too late in their programs or that it was focused on working in a narrow range of practice areas. They recognised that the process of becoming 'job ready' needed to start earlier and be embedded throughout degrees. There was variation within this subtheme as some participants reported they were well prepared by their university to secure work. These participants recalled benefitting from career development activities such as workshops facilitated by their universities and hearing guest presenters discuss job interview techniques.

\section{Going it alone}

A lack of support while transitioning into the workforce as a graduate dietitian was apparent within this subtheme. This 'lonely' and 'isolating' experience impacted graduates' trajectory into working life. While some cited the Dietitians Association of Australia (DAA) accredited practising dietitian (APD) program as a means to assisting with their broader professional development, they felt there was nowhere to go if they had questions regarding day-to-day practice issues. The lack of support experienced was particularly evident for graduates entering into roles without dietitian colleagues or for graduates commencing work in emerging fields (e.g. private practice). Having a mentor through the formal DAA APD program was described by some as 'invaluable.' However, other participants reported shortcomings of this system, including that some mentors offered their services at a financial cost to graduates. Some participants described the profession as unsupportive of graduates and recognised the need for better networks to be established between graduates and universities, practitioners, mentors and the professional association. 


\section{Having support}

Being well supported was integral to graduates in their pursuit of work and adapting to life as a dietetics professional. Those graduates who were 'lucky' enough to benefit from having assistance cited mentors, peers, employers and dietitian colleagues in their workplace as making the process easier. Some participants felt well-supported by their university and rated educators as 'excellent' supporters, while others were vocal about being left to work things out for themselves as soon as they completed their degree. Some took steps to ensure that support was provided and established their own networks by joining groups and seeking out good mentors.

\section{Discussion}

This is the first study to take a national approach to exploring recent dietetics graduates' broad experiences of being prepared as a dietitian in Australia. The five themes identified were: (1) being held back; (2) chasing the prize; (3) valuing real learning; (4) easing the transition; and (5) encountering influencers. While graduates reflected positively on their preparation, they described not being empowered or equipped to embrace opportunities in what they perceived to be more diverse and emerging areas of practice. Graduates were challenged by the competitive landscape of securing obvious job opportunities and by a lack of support in entering and acclimatizing to the workforce. Exposures to practice settings and encounters with influential dietitians enabled the fulfillment of graduates' dietetics aspirations and were highly valued. While this research has focused on the profession of dietetics, the findings discussed here can be used by health professional educators and researchers more broadly, to consider how graduates' experiences may be used to inform curriculum renewal and thereby optimise future health professional graduate outcomes.

Producing graduates who are underprepared to embrace a range of existing and emerging opportunities is of concern. An overemphasis on preparing graduates for traditional areas (e.g. clinical dietetics) as described by the participants in this study reflects the views of other key stakeholders in dietetics workforce preparation (i.e. practice educators, students) (Morgan et al. 2019a, b). These findings are incongruent with the professional association's intention to "prepare competent graduate dietitians through a 'generalist' education...to capitalise on the variety of opportunities that now exist in the Australian food and nutrition industry" (Dietitians Association of Australia 2018c). They also strengthen the 'underprepared' and 'overproduced' scenario previously hypothesised by leaders in the profession, whereby dietetics education programs produce too many graduates with too few skills relevant to future workforce needs (Rhea and Bettles 2012a). To ensure that tomorrow's dietitians are equipped to embrace an array of opportunities, dietetics education programs, and the accreditation standards that underpin them, must reflect contemporary practice. Considerable leadership has been shown in the UK and USA where research has been commissioned to envision the future direction of the dietetics profession (Rhea and Bettles 2012b; Hickson et al. 2017; Kicklighter et al. 2017). Conducting similar research in Australia to ensure that dietitians, and the programs preparing them, are responsive and relevant would benefit both the existing and emerging dietetics workforce.

Participants' disenchantment at having to fiercely compete for employment significantly impacted their experience of entering the workforce. Despite the participant characteristics indicating that most of these graduates secured some form of work quite quickly, their 
insights revealed this experience could be much improved. Even those who were successful in securing work easily recognised that they were 'lucky'. While data on dietetics graduate outcomes in Australia is lacking (Morgan et al. 2019c), this strong competition for obvious job opportunities as a result of a perceived graduate oversupply has been confirmed by dietetics educators in both academic and practice settings (Morgan et al. 2018, 2019b). These findings support the need to address the competitive landscape resulting from supply/demand mismatches that exist within dietetics internationally (Nyland and Lafferty 2012; Ruhl and Lordly 2017; Morgan et al. 2019a). Providing students with experiences across diverse practice contexts to illustrate the breadth of possible careers is one potential strategy. An established body of evidence regarding role-emerging placements, which can promote a profession's expansion into new areas and serve as a precursor to graduate employment (Rodger et al. 2007; Dancza et al. 2013), exists for occupational therapy (Clarke et al. 2014). These placements have been trialled in dietetics (Mackenzie and Newman 2017). However, significantly more research to support educators to implement student placements in emerging dietetics settings is needed.

It is well-recognised that the transition from student to health professional can be challenging (Department of Health 2013; Duchscher and Windey 2018). For the graduates in this study, a lack of support and guidance throughout this pivotal process resulted in a sense of trepidation, isolation and conjecture. This sentiment was notably pronounced for graduates entering, or attempting to enter, sole practitioner roles (e.g. private practice). While there is no published data to enumerate dietetics graduates embarking on careers in private practice in Australia, this apparent growth of unsupported and underprepared newly graduated dietitians is considered a 'risk' to the profession (Morgan et al. 2019b). Existing mechanisms for supporting novice dietitians in Australia [e.g. a formal mentoring program (Dietitians Association of Australia 2018d), an interest group (Dietitians Association of Australia 2015), webinars (Dietitian Connection 2018b) and coaching sessions (Dietitian Connection 2018a)], often come at a financial cost and are not always known to, or actioned by, graduates until the conclusion of university. There remains an obvious gap for dietetics educators to more astutely assist dietetics graduates to search for, secure and adjust to work earlier in their preparation.

Encouraging students to engage in both formal and informal interactions throughout university can lead to enhanced and collaborative learning (Hommes et al. 2012). Adopting such a strategy in dietetics could result in graduates who, as a group, support each other, address common issues and share resources throughout their transition into the workforce. In addition, this could strengthen ties between students/graduates while reducing competition and enhancing collaboration among emerging dietitians. Moreover, exposing students to potential mentors (either from dietetics or other related fields e.g. business) and empowering them to initiate mentoring relationships from the commencement of their degrees could ease the student-to-professional transition.

The fulfillment that graduates in this study derived from authentic exposures validates the andragogical value of active learning. However, participants' recognition of theory and practice as separate entities which were not well-integrated may highlight deficiencies in dietetics education in Australia. Further, graduates' propensity to reflect on their preparation as occurring in siloes or discrete domains (e.g. clinical dietetics, community and public health nutrition, and food service) is also noteworthy. These findings allude to the possibility that dietetics is yet to fully embrace evidence generated from contemporary health professional education research regarding holistic approaches to preparation. For example, taking programmatic and systems-based approaches to assessment and curriculum design (Schuwirth and Ash 2013; Palermo et al. 2017; Obeso et al. 2018). It also reaffirms the 
notion that dietetics graduates are not true generalists. Given the recognised need for health professionals who can adapt to our ever-changing health care landscape, producing competent generalists who are empowered to create opportunities regardless of the context in which they work has been proposed as one solution (Hudson et al. 2017). Stakeholders in dietetics education must ensure that dietetics education programs are holistic in nature, with theory and practice effectively integrated and embedded to expedite the performance of students and therefore graduates.

The findings of this study strengthen and reiterate the case for the collection and dissemination of up-to-date data on the dietetics workforce in Australia. Dietetics does not benefit from the consistent and coordinated workforce data collection services provided to other registered professions by the Australian Health Practitioner Regulation Agency (Australian Health Practitioner Regulation Agency 2018). Further, the professional dietetics association does not publish information on the characteristics of the workforce that it represents, including that of dietetics students and graduates. The last time that graduate outcomes for a national sample of recently graduated dietitians was reported in Australia was over 25 years ago (Scott 1991). As a result of this evidence gap, it is impossible to assess if samples such as the one in this study are representative of the population of recent graduates. Dietetics stakeholders, such as researchers and educators, are also unable to analyse how the workforce is evolving and to adapt dietetics education curricula accordingly. This significantly limits the profession's ability to progress. Robust and regularly collected dietetics workforce data in Australia is urgently needed.

Viewing the results of this study through the lens of self-determination theory (Ryan and Deci 2000; Ten Cate et al. 2011) can help to understand the meaning that participants attributed to their experiences of dietetics workforce preparation and preparedness. In accordance with this theory, an individual's motivation to learn, seek out challenges and optimally function, depends on the satisfaction of three innate needsautonomy, competence and relatedness. Situations that thwart the satisfaction of these needs result in reduced motivation for individuals. Graduates demonstrated their need for autonomy (desire to control one's own destiny) through their sentiments of disenchantment at difficulties experienced while trying to enter the workforce. Their need for competence (desire to be effective in activities pursued) was evident in their fulfillment from being able to participate in 'real' learning experiences in practice settings. The satisfaction that participants expressed around their encounters with influential dietitians was indicative of their need for relatedness (desire for belonging and connectedness with significant others). A greater understanding of students' and graduates' selfdetermined motivations can assist dietetics education stakeholders to develop contexts that support their desires for achieving optimal growth. For example, if students are motivated by their pursuit of experiential activities in practice settings, educators may need to ensure the inclusion of work-integrated learning exercises from early on in students' preparation.

Finally, it is prudent to reiterate the epistemological and theoretical stances taken in this research and how they have influenced the findings presented. While these graduates' accounts add to the existing body of empirical evidence regarding emerging health professionals' perspectives on their education, they do not purport to present one single objective reality. Rather, these findings represent the multiple 'realities' that have been socially constructed by the participants and their interactions with the world. The active involvement of students and graduates in health professional education scholarship has previously been acknowledged as an important strategy to help bridge the preparation-practice gap, as well as developing agency in future practitioners (Barradell et al. 2018). This study adds weight 
to the case for seeking out these constructed realities and engaging students and graduates as partners in learning and teaching (Barradell et al. 2018).

\section{Strengths and limitations}

A key strength of this study was the diversity of participant characteristics. The national sample of graduates from a range of locations across the country enhances transferability of the study's findings to other contexts. Participants were ideally-placed to reflect on their experience as a student, while also having the context of being (or attempting to be) a dietitian in the workforce. The multianalyst approach to code checking, transcript auditing and development of themes promoted interpretive validity (Sandelowski 2000) and helped to ensure rigour in determining when the research question had been addressed (Varpio et al. 2017). Reflexivity (Willig 2013) was enhanced through multiple, robust discussions during data analysis and by all researchers acknowledging their positions in relation to the research topic. Interviews were conducted in a uniform manner and by a researcher unknown to the participants to ensure descriptive validity (Sandelowski 2000) while open-ended questions minimised researcher influence on participant responses. The use of template analysis in the development of themes (Brooks et al. 2015) helped to account for any influence from similar studies conducted by the research team.

The significant lack of empirical, current and in-depth data regarding the dietetics workforce in Australia is a limitation of this study. Findings have been interpreted without robust information to describe the settings in which graduate dietitians are working and how this emerging workforce is evolving. While sampling methods attempted to limit self-selection bias, the self-nominating participants could have been more motivated to share memorable (i.e. very good or very bad) experiences of their education. This may limit the transferability of this study's findings to other contexts as these experiences may or may not be shared by other dietetics graduates. Another potential limitation pertains to the revised competency and accreditation standards for dietetics education programs in Australia which were being phased in at the time of this study. Ongoing research may illustrate if and how these updated standards have since impacted dietetics graduates' experiences of their preparation. The sample size used here is consistent with accepted qualitative research methods aimed at obtaining richly detailed descriptions from individuals about a phenomenon of interest and is not considered a limitation.

\section{Implications for future practice and research}

This study has been unique in bringing forward the graduate voice regarding their education and has implications for stakeholders involved in health workforce preparation. It provides a 'case' in dietetics by which other health professions might be encouraged to actively seek the viewpoints of emerging practitioners when renewing curricula. Recent graduates are well-placed informants to comment on their preparation and preparedness for practice, yet few studies have taken a national approach to gain in-depth insights of these phenomena. This study provides impetus for educators and researchers in other countries, and in other health professions, to broadly explore how emerging practitioners view their training and work-readiness. A robust analysis of the current and future state of the existing and emerging dietetics workforce in Australia is urgently needed. Further, assessing the viability of role-emerging student placements in health 
professions witnessing role expansion, such as dietetics, is also warranted. Dietetics may also benefit from adopting strategies shown to be effective in other health professions that support, mentor and enhance graduates' transition into the workforce. Finally, future research that focuses on potential solutions which may address the challenges raised by the participants in this study will only serve to benefit the rapidly growing and potentially-impactful dietetics profession. Addressing these suggestions could help to inform curricula and produce graduates that are responsive and relevant to future health and health workforce needs.

\section{Conclusions}

Recent dietetics graduates provide important insights on an emerging and evolving workforce that is well-placed to advance global health. While they are fulfilled by experiential professional activities and encounters with influential dietitians, dietetics graduates feel disenchanted by being prepared for a narrow range of practice areas and by a lack of workforce transition guidance. To ensure that the emerging dietetics workforce is responsive and relevant to future workforce and health needs, dietetics education programs and the standards that underpin them must consider graduates' perspectives on their preparation and respond accordingly. Research on role-emerging dietetics placements along with enhanced support mechanisms for novice dietitians and robust dietetics workforce data is urgently required to ensure that future dietetics preparation and practice are appropriately aligned. While the findings of this study have been generated through exploring the experiences of dietetics graduates, they have relevance and application for enhancing the preparation and preparedness of future workforces across all health professions.

Acknowledgements The authors wish to thank the twenty dietetics graduates who participated in this study and shared their experiences of dietetics workforce preparation and preparedness.

Funding This research was supported in part, by an Australian Government Research Training Program Scholarship. The funding body had no involvement in this study.

\section{Compliance with ethical standards}

Conflict of interest The authors declare that they have no conflict of interest.

\section{References}

Atkinson, R., \& McElroy, T. (2016). Preparedness for physiotherapy in private practice: Novices identify key factors in an interpretive description study. Manual Therapy, 22, 116-121.

Australian Health Practitioner Regulation Agency. (2018). Data access and research. Retrieved 5 September, 2018, from https://www.ahpra.gov.au/About-AHPRA/What-We-Do/Data-access-and-resea rch.aspx.

Barr, J., Ogden, K., Rooney, K., \& Robertson, I. (2017). Preparedness for practice: The perceptions of graduates of a regional clinical school. Medical Journal of Australia, 206(10), 447-452.

Barradell, S., Peseta, T., \& Barrie, S. (2018). 'There's so much to it': The ways physiotherapy students and recent graduates experience practice. Advances in Health Sciences Education, 23(2), 387-406.

Brady, J., Lordly, D., MacLellan, D., \& Gingras, J. (2012). New dietetic practitioners' perspectives: On their education and training. Canadian Journal of Dietetic Practice and Research, 73(3), 117-121. 
Braun, V., \& Clarke, V. (2006). Using thematic analysis in psychology. Qualitative Research in Psychology, 3(2), 77-101.

Brissette, C., Leung, E., Darling, P. B., \& Keith, M. (2014). Reflections on perceived preparedness of dietetic internship graduates following entry into practice. Canadian Journal of Dietetic Practice and Research, 75(4), 202-205.

Brooks, J., McCluskey, S., King, N., \& Turley, E. (2015). The utility of template analysis in qualitative psychology research. Qualitative Research in Psychology, 12(2), 202-222.

Brown, L., Capra, S., \& Williams, L. (2006). Profile of the Australian dietetic workforce: 1991-2005. Nutrition \& Dietetics, 63(3), 166-178.

Bunce, L., Baird, A., \& Jones, S. E. (2017). The student-as-consumer approach in higher education and its effects on academic performance. Studies in Higher Education, 42(11), 1958-1978.

Clarke, C., de Visser, R., Martin, M., \& Sadlo, G. (2014). Role-emerging placements: A useful model for occupational therapy practice education? A review of the literature. International Journal of Practice-based Learning in Health and Social Care, 2(2), 14-26.

Creswell, J. W. (2013). Qualitative inquiry and research design: Choosing among five approaches. Thousand Oaks, CA: SAGE Publications.

Creswell, J. W., \& Poth, C. N. (2018). Qualitative inquiry and research design: Choosing among five approaches. Los Angeles: SAGE.

Crotty, M. (1998). The foundations of social research: Meaning and perspective in the research process. St. Leonards, NSW: Allen \& Unwin.

Dancza, K., Warren, A., Copley, J., Rodger, S., Moran, M., McKay, E., et al. (2013). Learning experiences on role-emerging placements: An exploration from the students' perspective. Australian Occupational Therapy Journal, 60(6), 427-435.

Darnton-Hill, I., Nishida, C., \& James, W. P. T. (2004). A life course approach to diet, nutrition and the prevention of chronic diseases. Public Health Nutrition, 7(1a), 101-121.

Department of Health. (2013). Statewide interprofessional allied health graduate program manual. Melbourne: Victorian Government.

Dey, I. (1999). Grounding grounded theory: Guidelines for grounded theory inquiry. San Diego: Academic Press.

Dietitians Association of Australia. (2012). Dietitians Association of Australia skilled occupations list 2012 submission. Dietitians Association of Australia. Deakin, ACT. Retrieved 21 February 2014, from http://www.awpa.gov.au/our-work/labour-market-information/skilled-occupation-list/Docum ents/DietitiansAssociationofAustralia.pdf.

Dietitians Association of Australia. (2015). Emerging dietitians terms of reference. Retrieved 5 September, 2018, from https://daa.asn.au/wp-content/uploads/2016/11/Emerging-Dietitians-TOR.pdf.

Dietitians Association of Australia. (2017). Accreditation Standards for Dietetics Education Programs Version 2.0. Dietitians Association of Australia. Canberra, ACT.

Dietitians Association of Australia. (2018a). Accredited dietetics education programs. Retrieved 7 September, 2018, from https://daa.asn.au/becoming-a-dietitian-in-australia/currently-accredited-diete tic-programs/.

Dietitians Association of Australia. (2018b). Accredited practising dietitian program. Retrieved 7 September, 2018, from https://daa.asn.au/apd-program/.

Dietitians Association of Australia. (2018c). Dietitian scope of practice. Retrieved 3 September, 2018, from https://daa.asn.au/maintaining-professional-standards/dietitian-scope-of-practice/.

Dietitians Association of Australia. (2018d). Provisonal APD program. Retrieved 4 September, 2018, from https://daa.asn.au/apd-program/apd-program-handbook/provisonal-apd-program/.

Dietitian Connection. (2018a). Coaching to get that job! Retrieved 5 September, 2018, from https://dieti tianconnection.com/uncategorised/recruitment-coaching-to-get-that-job/.

Dietitian Connection. (2018b). How to get that job webinar series. Retrieved 5 September, 2018, from https ://dietitianconnection.com/product/how-to-get-that-job-webinar-series/.

Duchscher, J. B., \& Windey, M. (2018). Stages of transition and transition shock. Journal for Nurses in Professional Development, 34(4), 228-232.

Gray, M., Clark, M., Penman, M., Smith, J., Bell, J., Thomas, Y., et al. (2012). New graduate occupational therapists feelings of preparedness for practice in Australia and Aotearoa/New Zealand. Australian Occupational Therapy Journal, 59(6), 445-455.

Halcomb, E. J., Salamonson, Y., Raymond, D., \& Knox, N. (2012). Graduating nursing students' perceived preparedness for working in critical care areas. Journal of Advanced Nursing, 68(10), 2229-2236.

Hatzenbuhler, N. J. \& Klein, J. E. (2018). Educational preparation for clinical practice: Reflections of newly graduated RNs. Nurse Educator, Publish Ahead of Print. 
Health Workforce Australia. (2014). Australia's health workforce series-Dietitians in focus. Health Workforce Australia. Adelaide. Retrieved 21 March 2014, from http://www.health.gov.au/internet/main/ publishing.nsf/Content/hwa-archived-publications.

Hickson, M., Child, J., \& Collinson, A. (2017). Future Dietitian 2025: Informing the development of a workforce strategy for dietetics. Journal of Human Nutrition \& Dietetics, 31, 23-32.

Hodgetts, S., Hollis, V., Triska, O., Dennis, S., Madill, H., \& Taylor, E. (2007). Occupational therapy students' and graduates' satisfaction with professional education and preparedness for practice. Canadian Journal of Occupational Therapy, 74(3), 148-160.

Hommes, J., Rienties, B., de Grave, W., Bos, G., Schuwirth, L., \& Scherpbier, A. (2012). Visualising the invisible: A network approach to reveal the informal social side of student learning. Advances in Health Sciences Education, 17(5), 743-757.

Hudson, J., Weston, K., \& Farmer, E. (2017). Changes in medical education to help physicians meet future health care needs. The Medical Journal of Australia, 206(9), 378-379.

Hunt, M. R. (2009). Strengths and challenges in the use of interpretive description: Reflections arising from a study of the moral experience of health professionals in humanitarian work. Qualitative Health Research, 19(9), 1284-1292.

Institute of Medicine. (2003). Health professions education: A bridge to quality. Washington, DC: The National Academies Press.

International Confederation of Dietetic Associations. (2016). Dietitians-nutritionists around the WorldTheir education and their work (2016). ICDA. Toronto. http://www.internationaldietetics.org/Downl oads/2016-ICDA-Education-Work-report.aspx.

Jones, M., McIntyre, J., \& Naylor, S. (2010). Are physiotherapy students adequately prepared to successfully gain employment? Physiotherapy, 96(2), 169-175.

Kairuz, T., Noble, C., \& Shaw, J. (2010). Preceptors, interns, and newly registered pharmacists' perceptions of New Zealand pharmacy graduates' preparedness to practice. American Journal of Pharmaceutical Education, 74(6), 1-6.

Kellett, J., Papageorgiou, A., Cavenagh, P., Salter, C., Miles, S., \& Leinster, S. J. (2015). The preparedness of newly qualified doctors-Views of Foundation doctors and supervisors. Medical Teacher, 37(10), 949-954.

Kicklighter, J. R., Dorner, B., Hunter, A. M., Kyle, M., Pflugh Prescott, M., Roberts, S., et al. (2017). Visioning report 2017: A preferred path forward for the nutrition and dietetics profession. Journal of the Academy of Nutrition and Dietetics, 117(1), 110-127.

Liamputtong, P. (2013). Qualitative research methods. South Melbourne, VIC: Oxford University Press.

Liamputtong, P., Beeson, M., \& Hameiri, S. (2017). Research methods in health: Foundations for evidencebased practice. South Melbourne, VIC: Oxford University Press.

Mackenzie, M., \& Newman, E. (2017). Preparing the dietetic workforce of the future: Developing innovative placements in social care settings. International Journal of Practice-based Learning in Health and Social Care, 5(1), 65-76.

Maher, J., Pelly, F., Swanepoel, E., Sutakowsky, L., \& Hughes, R. (2015). The contribution of clinical placement to nutrition and dietetics competency development: A student-centred approach. Nutrition \& Dietetics, 72(2), 156-162.

Morgan, K., Campbell, K. L., \& Reidlinger, D. P. (2019a). Dietetics students' experiences of dietetics workforce preparation and preparedness: A systematic review and qualitative synthesis. Journal of Human Nutrition \& Dietetics, 32(2), 226-246.

Morgan, K., Campbell, K. L., Sargeant, S., \& Reidlinger, D. P. (2019b). Preparing our future workforce: A qualitative exploration of dietetics practice educators' experiences. Journal of Human Nutrition \& Dietetics, 32(2), 247-258.

Morgan, K., Kelly, J. T., Campbell, K. L., Hughes, R., \& Reidlinger, D. P. (2019c). Dietetics workforce preparation and preparedness in Australia: A systematic mapping review to inform future dietetics education research. Nutrition \& Dietetics, 76(1), 47-56.

Morgan, K., Reidlinger, D. P., Sargeant, S., Crane, L. \& Campbell, K. L. (2018). Challenges in preparing the dietetics workforce of the future: An exploration of dietetics educators' experiences. Nutrition \& Dietetics (In press) https://doi.org/10.1111/1747-0080.12438 (Epub ahead of print).

Morrow, G., Johnson, N., Burford, B., Rothwell, C., Spencer, J., Peile, E., et al. (2012). Preparedness for practice: The perceptions of medical graduates and clinical teams. Medical Teacher, 34(2), 123-135.

Noble, C., O’Brien, M., Coombes, I., Shaw, P. N., Nissen, L., \& Clavarino, A. (2014). Becoming a pharmacist: Students' perceptions of their curricular experience and professional identity formation. Currents in Pharmacy Teaching and Learning, 6(3), 327-339.

Nyland, N., \& Lafferty, L. (2012). Implications of the dietetics workforce demand study. Journal of the Academy of Nutrition and Dietetics, 112(3), S92-S94. 
Obeso, V. T., Phillipi, C. A., Degnon, C. A., Carter, T. J., Aiyer, M., Baron, B., et al. (2018). A systemsbased approach to curriculum development and assessment of core entrustable professional activities in undergraduate medical education. Medical Science Educator, 28(2), 407-416.

O’Brien, B. C., Harris, I. B., Beckman, T. J., Reed, D. A., \& Cook, D. A. (2014). Standards for reporting qualitative research: A synthesis of recommendations. Academic Medicine: Journal of the Association of American Medical Colleges, 89(9), 1245.

Palermo, C., Chung, A., Beck, E. J., Ash, S., Capra, S., Truby, H., et al. (2015). Evaluation of assessment in the context of work-based learning: Qualitative perspectives of new graduates. Nutrition \& Dietetics, 72(2), 143-149.

Palermo, C., Gibson, S. J., Dart, J., Whelan, K., \& Hay, M. (2017). Programmatic assessment of competence in dietetics: A new frontier. Journal of the Academy of Nutrition and Dietetics, 117(2), 175-179.

Palermo, C., Hughes, R., \& McCall, L. (2011). A qualitative evaluation of an Australian public health nutrition workforce development intervention involving mentoring circles. Public Health Nutrition, 14(08), $1458-1465$.

Patton, M. Q. (2015). Qualitative research and evaluation methods: Integrating theory and practice. Thousand Oaks, CA: SAGE Publications.

Rhea, M., \& Bettles, C. (2012a). Four futures for dietetics workforce supply and demand: 2012-2022 Scenarios. Journal of the Academy of Nutrition and Dietetics, 112(3), S25-S34.

Rhea, M., \& Bettles, C. (2012b). Future changes driving dietetics workforce supply and demand: Future scan 2012-2022. Journal of the Academy of Nutrition and Dietetics, 112(3), S10-S24.

Rodger, S., Thomas, Y., Dickson, D., McBryde, C., Broadbridge, J., Hawkins, R., et al. (2007). Putting students to work: Valuing fieldwork placements as a mechanism for recruitment and shaping the future occupational therapy workforce. Australian Occupational Therapy Journal, 54(s1), S94-S97.

Rose, M., McAlpine, L., \& Strychar, I. (2005). Learning opportunity and preparedness for practice: Perceptions from dietetics programs in Canada. Canadian Journal of Dietetic Practice and Research, 66(4), 221-228.

Ruel, G., Shi, Z., Zhen, S., Zuo, H., Kroger, E., Sirois, C., et al. (2014). Association between nutrition and the evolution of multimorbidity: The importance of fruits and vegetables and whole grain products. Clinical Nutrition, 33(3), 513-520.

Ruhl, J. M., \& Lordly, D. (2017). The nature of competition in dietetics education: A narrative review. Canadian Journal of Dietetic Practice and Research, 78(3), 129-136.

Ryan, R. M., \& Deci, E. L. (2000). Self-determination theory and the facilitation of intrinsic motivation, social development, and well-being. American Psychologist, 55(1), 68-78.

Sandelowski, M. (2000). Whatever happened to qualitative description? Research in Nursing \& Health, 23(4), 334-340.

Schuwirth, L., \& Ash, J. (2013). Assessing tomorrow's learners: In competency-based education only a radically different holistic method of assessment will work. Six things we could forget. Medical Teacher, 35(7), 555-559.

Scott, J. (1991). A survey of recent graduate dietitians: Career choices, plans and aspirations and satisfaction with academic preparation. Australian Journal of Nutrition and Dietetics, 48(4), 132-138.

Ten Cate, T. J., Kusurkar, R. A., \& Williams, G. C. (2011). How self-determination theory can assist our understanding of the teaching and learning processes in medical education. AMEE guide No. 59. Medical Teacher, 33(12), 961-973.

Thorne, S. E. (2016). Interpretive description: Qualitative research for applied practice. London, UK: Routledge.

Tomlinson, M. (2016). The impact of market-driven higher education on student-university relations: Investing. Consuming and Competing. Higher Education Policy, 29(2), 149-166.

Varpio, L., Ajjawi, R., Monrouxe, L. V., O’Brien, B. C., \& Rees, C. E. (2017). Shedding the cobra effect: Problematising thematic emergence, triangulation, saturation and member checking. Medical Education, 51(1), 40-50.

Willig, C. (2013). Introducing qualitative research in psychology. Buckingham: McGraw-Hill Education.

World Health Organization. (2006). The world health report 2006: Working together for health. Geneva: World Health Organization.

Publisher's Note Springer Nature remains neutral with regard to jurisdictional claims in published maps and institutional affiliations. 